\title{
Change-Point Analysis
}

National Cancer Institute

\section{Source}

National Cancer Institute. Change-Point Analysis. NCI Thesaurus. Code C64211.

Methods for determining whether a change has taken place, when it has taken place, the confidence level indicating the likelihood that a change occurred, and the confidence interval indicating when the change occurred. 